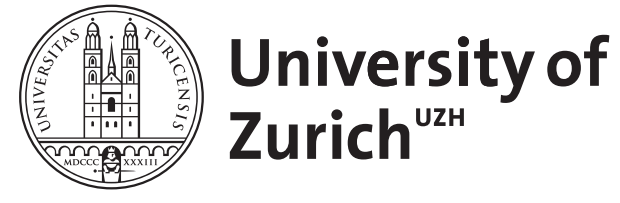
Archive

University of Zurich

University Library

Strickhofstrasse 39

CH-8057 Zurich

www.zora.uzh.ch

Year: 2012

Metal Ion-RNA interactions studied via multinuclear NMR

Donghi, D ; Sigel, Roland K O

DOI: https://doi.org/10.1007/978-1-61779-545-9_16

Posted at the Zurich Open Repository and Archive, University of Zurich

ZORA URL: https://doi.org/10.5167/uzh-75264

Journal Article

Accepted Version

Originally published at:

Donghi, D; Sigel, Roland K O (2012). Metal Ion-RNA interactions studied via multinuclear NMR. Methods in Molecular Biology, (848):253-274.

DOI: https://doi.org/10.1007/978-1-61779-545-9_16 


\title{
Methods in Molecular Biology
}

\section{Ribozymes}

\author{
Chapter 16
}

\section{Metal Ion-RNA Interactions Studied via Multinuclear NMR}

\author{
Daniela Donghi and Roland K. O. Sigel* \\ Institute of Inorganic Chemistry, University of Zurich, Winterthurerstrasse 190, \\ CH-8057 Zurich, Switzerland; *email, roland.sigel@aci.uzh.ch
}

Running Head: Metal ion-RNA interactions 


\begin{abstract}
Metal ions are indispensable for ribonucleic acids (RNAs) folding and activity. Firstly they act as charge neutralization agents, allowing the RNA molecule to attain the complex active three dimensional structure. Secondly, metal ions are eventually directly involved in function. Nuclear magnetic resonance (NMR) spectroscopy offers several ways to study the RNAmetal ion interactions at an atomic level. Here we first focus on special requirements for NMR sample preparation for this kind of experiments: the practical aspects of in vitro transcription and purification of small $(<50 \mathrm{nt}) \mathrm{RNA}$ fragments is described, as well as the precautions that must be taken into account when a sample for metal ion titration experiments is prepared. Subsequently, we discuss the NMR techniques to accurately locate and characterize metal ion binding sites in a large RNA. For example, ${ }^{2} J-\left[{ }^{1} \mathrm{H},{ }^{15} \mathrm{~N}\right]-\mathrm{HSQC}$ (Heteronuclear Single Quantum Coherence) experiments are described to qualitatively distinguish between different modes of interaction. Finally, part of this last section is devoted to data analysis, this is how to calculate intrinsic affinity constants.
\end{abstract}

Keywords: Ribonucleic acids; metal ions; in vitro transcription; nuclear magnetic resonance spectroscopy; chemical shift perturbation; affinity constants.

\title{
1. Introduction
}

Ribonucleic acids are not simple working copies of the genome, but rather play crucial roles in a large number of biological functions (1). Since the discovery of catalytically active RNAs in the early eighties, i.e. ribozymes $(\mathbf{2}, \mathbf{3})$, the research aimed at understanding structure and function of RNAs has remarkably increased.

Due to their polyanionic nature, RNAs are intrinsically associated with metal ions (4). In 
general, metal ions are diffusely bound to RNAs, acting primarily as charge screening agents. However it has been shown that around $10 \%$ of the total negative charge is compensated by metal ions that are site specifically bound (5). In order to be active, RNA molecules need to adopt complex three dimensional structures, stabilized by a large number and variety of tertiary contacts. In this folding process, localized pockets of accumulated negative charge are formed, that strongly bind positively charged ions, that is $\mathrm{Na}^{+}, \mathrm{K}^{+}, \mathrm{Ca}^{2+}$ and $\mathrm{Mg}^{2+}$, the most abundant solvated metal ions in cells (5). In particular, $\mathrm{Mg}^{2+}$ has been shown to perform both a structural and a catalytical role. For example, the presence of two $\mathrm{Mg}^{2+}$ ions in the catalytic core of group I and group II introns, as revealed by recent X-ray structures, strongly supports the hypothesis of a two metal ion mechanism for the catalysis performed by these two classes of large ribozymes $(\mathbf{6}, \mathbf{7})$. Hence, the study of the interaction between metal ions and RNA has a double significance: it allows to characterize and understand the structural arrangement as well as the functioning of these large biomolecules, both being tightly interlinked.

NMR is a powerful technique able to provide information on biologically relevant molecules at the atomic level (8). Mostly, RNAs comprising 20 to 40 nucleotides are studied by NMR, but recently also NMR structures of RNAs in the size range of $25-40 \mathrm{kDa}$ have been described $(\mathbf{8}, \mathbf{9})$. For a detailed description on the use of NMR for RNA structural studies please refer to Chapter 12 of this volume. The study of RNA-metal ion interactions by NMR is challenging, as the exchange rate of metal ions in RNA-metal systems is equal or faster than the NMR time scale. The resulting line broadening consequently hampers evaluation and characterization of the exact interaction.

The biologically most relevant metal ion in RNA biochemistry is $\mathrm{Mg}^{2+}$, which is commonly considered as spectroscopically silent (5). It is however worth mentioning that $\mathrm{Mg}^{2+}$ is $\mathrm{NMR}$ active, and, despite its low sensitivity, low natural abundance and its large quadrupolar moment, a few reports have been published dealing with the use of this "exotic" nucleus in the 
study of NTPs- $\mathrm{Mg}^{2+}$ as well as nucleic acids- $\mathrm{Mg}^{2+}$ interactions (for a recent review, see (10)). For example, by ${ }^{25} \mathrm{Mg}$ NMR line shape analysis of RNAs titrated with isotopically enriched $\mathrm{Mg}^{2+}$ it was possible to estimate the numbers and the association constants of weakly bound $\mathrm{Mg}^{2+}$ to tRNAs (11). However, in order to localize and quantify RNA-metal ion interactions by $\mathrm{NMR},{ }^{1} \mathrm{H},{ }^{13} \mathrm{C},{ }^{15} \mathrm{~N}$ and ${ }^{31} \mathrm{P}$ are the nuclei normally applied. They all have spin $1 / 2$ and are straightforward to record and study. Moreover, the now easy and cost-affordable access to ${ }^{13} \mathrm{C}$ and ${ }^{15} \mathrm{~N}$ isotope labeled RNAs (12) overcomes the difficulties intrinsically related to the low receptivity and abundance of these nuclei. Nevertheless, it is worth noting that most of the biologically relevant metal ions are NMR active, but show low sensitivity and spins larger than $1 / 2$, resulting in broad signals not always easy to record.

RNA building blocks contain numerous metal ion binding atoms (Fig. 1): phosphoryl oxygens, guanosine O6, uracil O4 and purine N7 are the most important ones. The metal ions can coordinate either directly through inner-sphere interactions or through outer-sphere interactions, i.e. mediated through the hydrogen bonds of the coordinated water molecule (Fig. 2) (5). It is worth noting that the coordination properties of metal ions to single nucleotides can be directly translated to large nucleic acids (5).

Many studies have been devoted to the interaction between RNA and metal ions others than $\mathrm{Mg}^{2+}$ to better characterize this interaction. For example, $\mathrm{Mn}^{2+}$ is used in paramagnetic line broadening studies to probe for inner sphere interaction while $\left[\mathrm{Co}\left(\mathrm{NH}_{3}\right)_{6}\right]^{3+}$, with its kinetically inert amines, can mimic the outer-sphere interaction of $\left[\mathrm{Mg}\left(\mathrm{H}_{2} \mathrm{O}\right)_{6}\right]^{2+}$, yielding NOE cross peaks between the amine ligands and RNA protons $(\mathbf{1 3}, \mathbf{1 4})$. Also, $\mathrm{d}^{10}$ have been applied: for example, strong perturbations in ${ }^{15} \mathrm{~N},{ }^{13} \mathrm{C}$ and ${ }^{1} \mathrm{H}$ chemical shifts were observed upon titration of a hammerhead ribozyme metal binding site model with $\mathrm{Cd}^{2+}$ : a high-field shift of about 20 ppm for ${ }^{15} \mathrm{~N}$, and a low-field shift of 0.38 and 2.3 ppm for ${ }^{1} \mathrm{H}$ and ${ }^{13} \mathrm{C}$, respectively, confirm a direct coordination of $\mathrm{Cd}^{2+}$ to the $\mathrm{N} 7$ of a specific guanosine (15). 
When NMR active metal ions are used, ${ }^{15} \mathrm{~N}-\mathrm{M}^{\mathrm{n}+}$ direct scalar coupling constants are evidence of the interaction, as shown recently in a DNA duplex containing $\mathrm{Ag}^{+}(\mathbf{1 6}) .{ }^{2} J_{\mathrm{NN}}$ metal mediated couplings have been reported for $\mathrm{Hg}^{2+}$ mediated thymine-thymine basepairs (17). However, the chemical exchange within RNA-metal ions system mostly prevents direct observation of J-coupling (18). Lastly, also ${ }^{31} \mathrm{P}$ chemical shift perturbation can be used to explore RNA-metal ion interactions (19).

The $\mathrm{Mg}^{2+}$-RNA interaction is characterized by a general intrinsic lability and relatively low stability. Nevertheless, NMR titration experiments of RNA molecules with $\mathrm{Mg}^{2+}$ allow a detailed examination of simultaneous metal ion binding to various sites, as well as offer the possibility to calculate intrinsic binding affinities (20). In this protocol we first concentrate on the practical aspects of RNA sample preparation for such experiments. Then $\left[{ }^{1} \mathrm{H},{ }^{1} \mathrm{H}\right]-\mathrm{NOESY}$ (Nuclear Overhauser Effect Spectroscopy) and ${ }^{2} J-\left[{ }^{1} \mathrm{H},{ }^{15} \mathrm{~N}\right]-\mathrm{HSQC}$ experiments are described to follow $\mathrm{Mg}^{2+}$ binding by both ${ }^{1} \mathrm{H}$ and ${ }^{15} \mathrm{~N}$ chemical shift perturbation, resulting in complementary information. Perturbation of proton chemical shifts is caused by either electronic effects of metal ion binding, structure perturbation caused by metal binding in the vicinity or a combination of both. Often it is necessary to first identify the binding pocket in order to obtain quantitative information on the binding constants. On the other hand, observation of the directly involved nucleus is indispensable to study the way of interaction: for example ${ }^{15} \mathrm{~N}$ resonances allow to discriminate between inner- and outer- sphere interaction modes (21) (Fig. 2). Finally, in Notes 38, 39 and 40, the interaction between $\mathrm{Mg}^{2+}$ and the truncated but catalytically active D6-27 from the yeast mitochondrial Sc.ai5 $\gamma$ group II intron (Fig. 3) is described in more details as a practical example (20, 21).

\section{Materials}


All solutions must be prepared by using autoclaved bi-distilled water (18.2 $\mathrm{M} \Omega \mathrm{cm}$ resistivity at $25^{\circ} \mathrm{C}$ ), that is additionally filtered through sterile $0.2 \mu \mathrm{m}$ Filtropur syringe filters (Sarstedt) or Steritop ${ }^{\mathrm{TM}}$ bottle top filter units (Millipore). To this we refer as "ultrapure water" throughout the text. All NMR tubes, reaction vessels, pipette tips etc. used must be RNase free. All chemicals are purchased from either Fluka-Sigma-Aldrich or Brunschwig Chemie, at puriss p.a. or biograde, if not otherwise specified.

\subsection{In Vitro Transcription, Polyacrylamide Gel Electrophoresis (PAGE) Purification and}

\section{Electroelution.}

1. Stock solutions of nucleosides 5'-triphosphate (NTPs): adenosine 5'-triphosphate (ATP; GE Healthcare), guanosine 5'-triphosphate (GTP; GE Healthcare), cytidine 5'triphosphate (CTP; GE Healthcare), uridine 5'-triphosphate (UTP; Acros-Brunschwig). To prepare $1 \mathrm{~mL}$ of an about $200 \mathrm{mM}$ solution, weigh roughly $120 \mathrm{mg}$ of dried NTPs, add $20 \mu \mathrm{L}$ of $1 \mathrm{M}$ TRIS(2-Amino-2-hydroxymethyl-propane-1,3-diol)- $\mathrm{HCl}(\mathrm{pH} 7.5)$ (dissolve $60.57 \mathrm{~g}$ in $500 \mathrm{~mL}$ of ultrapure water, adjust the $\mathrm{pH}$ with $\mathrm{HCl}$ and store at room temperature) and $800 \mu \mathrm{L}$ ultrapure water and mix well. Adjust the $\mathrm{pH}$ to 7.0 with freshly prepared $5 \mathrm{M} \mathrm{NaOH}$ solution, and fill up to $1 \mathrm{~mL}$ (see Note 1). The exact concentration of the freshly prepared NTP solutions is determined by UV spectroscopy (see Note 2). Prepare 1-2 mL of NTP solutions, divide in $300-400 \mu \mathrm{L}$ aliquots and store them at $-20^{\circ} \mathrm{C}$. Use the NTP solutions within a few months.

2. $\mathrm{NaOH}$ and $\mathrm{HCl}$ solutions at different concentration: prepare $10 \mathrm{~mL}$ each of $5 \mathrm{M} \mathrm{NaOH}$ and $1 \mathrm{M} \mathrm{HCl}$ solutions. Lower concentrated stock solutions are obtained by dilution $(1 \mathrm{M}, 100$ $\mathrm{mM}, 10 \mathrm{mM}, 1 \mathrm{mM})$. Store at room temperature.

3. Transcription buffer (5x): $200 \mathrm{mM}$ TRIS-HCl (pH 7.5), $200 \mathrm{mM}$ DTT (Dithiothreitol) and $10 \mathrm{mM}$ spermidine (N-(3-aminopropyl)butane-1,4-diamine) in ultrapure water. For $1 \mathrm{~mL}$ 
of solution, mix $200 \mu \mathrm{L}$ of 1 M TRIS- $\mathrm{HCl}(\mathrm{pH} 7.5), 200 \mu \mathrm{L}$ of $1 \mathrm{M}$ DTT (154.25 mg in $1 \mathrm{~mL}$ of ultrapure water, store at $\left.-20^{\circ} \mathrm{C}\right), 5 \mu \mathrm{L}$ of $2 \mathrm{M}$ spermidine $(290.5 \mathrm{mg}$ in $1 \mathrm{~mL}$ of ultrapure water, store at $-20^{\circ} \mathrm{C}$ ) and $445 \mu \mathrm{L}$ of ultrapure water. Prepare $10-20 \mathrm{~mL}$ of transcription buffer solution and store it in $1 \mathrm{~mL}$ aliquots at $-20^{\circ} \mathrm{C}$. If properly stored, they can be used indefinitely.

4. Stock solutions of the two strands each of the double stranded DNA template comprising the $\mathrm{T} 7$ promoter region plus the coding region (22), prepared at a concentration between 50 and $200 \mu \mathrm{M}$ (checked with an UV spectrophotometer). The DNA strands are normally purchased from commercial suppliers (e.g. Microsynth) and purified by PAGE before usage (see Notes 3, 4 and 5). Store at $-20^{\circ} \mathrm{C}$.

5. Ultrapure $1 \mathrm{M} \mathrm{MgCl}_{2}$ solution in water, as purchased from the commercial supplier (see Note 6). Store at room temperature.

6. Homemade bacteriophage T7 RNA polymerase in $30 \%$ glycerol (see Note 7). Store at $-20^{\circ} \mathrm{C}$.

7. $\quad 100 \%$ and $70 \%$ ethanol. Store at room temperature.

8. $5 \mathrm{M} \mathrm{NaCl}$ in ultrapure water. Weigh $2.9 \mathrm{~g}$ of $\mathrm{NaCl}$ in a $12 \mathrm{~mL}$ plastic tube and add up to $10 \mathrm{~mL}$ total volume of ultrapure water. Mix vigorously. Store at room temperature.

9. Gel solution in ultrapure water, $7 \mathrm{M}$ urea (Eurobio), $89 \mathrm{mM} \mathrm{TBE}$ (TRIS/Borate/EDTA-ethylenediaminetetraaceticacid-), and five to twenty percent of polyacrylamide starting from a stock solution of $\mathrm{AccuGel}^{\mathrm{TM}}(40 \% \mathrm{w} / \mathrm{v} ; 29: 1$ acrylamide/bisacrylamide), depending on the size of the RNA under investigation (see Note 8). For example, to prepare $1 \mathrm{~L}$ of $18 \%$ gel solution, weigh $420 \mathrm{~g}$ of urea in a $1 \mathrm{~L}$ beaker, add $100 \mathrm{~mL}$ of $10 \mathrm{x}$ TBE (see below) and $450 \mathrm{~mL}$ of $40 \%$ AccuGel $^{\mathrm{TM}} 29: 1$ solution. Fill up to $1 \mathrm{~L}$ with ultrapure water. Mix with a magnetic stirrer for half an hour at $50-60^{\circ} \mathrm{C}$ to dissolve urea. Pass through a sterile filter and keep in a $1 \mathrm{~L}$ screwed cap autoclaved bottle. Store in the dark 
at $4^{\circ} \mathrm{C}$.

10. TBE running buffer (1x). Dilute $100 \mathrm{~mL}$ of commercially available $10 \mathrm{x}$ TBE $(0.89 \mathrm{M}$ TRIS Borate $\mathrm{pH} 8.9$, and $20 \mathrm{mM} \mathrm{Na}_{2}$ EDTA) to $1 \mathrm{~L}$ with ultrapure water. Transfer to a $1 \mathrm{~L}$ screwed cap bottle, mix and autoclave it. Prepare 3-5 L of running buffer. Store at room temperature.

11. TEMED (N,N,N',N'-tetramethyl-ethane-1,2-diamine), as purchased from the commercial supplier. Store at $4^{\circ} \mathrm{C}$.

12. Ammonium persulfate (APS) solution in ultrapure water, $10 \%(\mathrm{w} / \mathrm{v})$. Prepare $10 \mathrm{~mL}$ and store at $4^{\circ} \mathrm{C}$. Use within a few weeks.

13. Denaturing urea loading buffer. $11.8 \mathrm{M}$ Urea, $0.083 \%$ dyes, $8.3 \%$ sucrose, $4.2 \mathrm{mM}$ TRIS HCl (pH 7.5), 0.83 mM EDTA (pH 8.0). Prepare $50 \mathrm{~mL}$ of loading buffer: weigh $35.4 \mathrm{~g}$ of urea in a $50 \mathrm{~mL}$ falcon tube, add $4.15 \mathrm{~g}$ of sucrose, $0.21 \mathrm{~mL}$ of $1 \mathrm{M}$ TRIS- $\mathrm{HCl}(\mathrm{pH} 7.5)$, $0.415 \mathrm{~mL}$ of $0.1 \mathrm{M}$ EDTA ( $\mathrm{pH}$ 8), (dissolve $37.2 \mathrm{mg}$ of $\mathrm{Na}_{2}$ EDTA $2 \mathrm{H}_{2} \mathrm{O}$ in $1 \mathrm{~mL}$ of ultrapure water and adjust the $\mathrm{pH}), 2.075 \mathrm{~mL}$ of each dyes (starting from a $2 \%$ solution of dye). Fill up with ultrapure water. Store at $4^{\circ} \mathrm{C}($ see Note 9).

\subsection{Preparation, Purification and Concentration of the NMR Samples.}

1. $1 \mathrm{M} \mathrm{KCl}$ solution in ultrapure water (dissolve $37.25 \mathrm{~g}$ of $\mathrm{KCl}$ in $500 \mathrm{~mL}$ of ultrapure water, store at room temperature), and ultrapure water for the washing and concentration of the RNA samples.

2. For NMR sample preparation: $100 \% \mathrm{D}_{2} \mathrm{O}$ (Armar Chemicals, see Note 10), $1 \mathrm{M} \mathrm{KCl}$ in $\mathrm{D}_{2} \mathrm{O}(74.55 \mathrm{mg}$ in $1 \mathrm{~mL}), 1 \mathrm{mM} \mathrm{Na} \mathrm{EDTA}_{2}$ in $\mathrm{D}_{2} \mathrm{O}(3.36 \mathrm{mg}$ in $1 \mathrm{~mL}$, and further dilute 100 $\mu \mathrm{L}$ to $1 \mathrm{~mL}$ ), $\mathrm{DCl}$ and $\mathrm{NaOD}$ in $\mathrm{D}_{2} \mathrm{O}$ at different concentration (normally from $0.1 \mathrm{mM}$ to 100 $\mathrm{mM}$, starting from concentrated solution purchased from commercial suppliers) to adjust the $\mathrm{pH}$ of the sample. Prepare $1 \mathrm{~mL}$ aliquots of each needed reagents and store at $4^{\circ} \mathrm{C}$. 
3. For metal ion titration: $100 \mathrm{mM} \mathrm{MgCl}_{2}$ in $\mathrm{D}_{2} \mathrm{O}(95.21 \mathrm{mg}$ of ultra pure water free $\mathrm{MgCl}_{2}$ in $10 \mathrm{~mL}$ of $\mathrm{D}_{2} \mathrm{O}$ ). The exact concentration of the stock solution is determined by potentiometric $\mathrm{pH}$ titration employing EDTA (23). Store at room temperature.

\section{Methods}

It is important to always use latex gloves during sample preparation and manipulation. Human skin is a rich source of RNases and other contaminations that cause RNA degradation. If the sample tends to easily degrade, it is advisable to prepare fresh buffers and solution each time.

\subsection{In Vitro Transcription, Polyacrylamide Gel Electrophoresis (PAGE) Purification and}

\section{Electroelution.}

1. Slowly defreeze the NTPs, the transcription buffer and the two DNA strands solutions on ice. Mix the NTPs (see Note 11) (final concentration of $5 \mathrm{mM}$ ) with the transcription buffer (final concentration of 1x), $0.01 \%$ (w/v) Triton X-100 (polyethylene glycol p-(1,1,3,3tetramethylbutyl)-phenyl ether) and ultrapure water in a $12 \mathrm{~mL}$ plastic tube. According to the efficiency of the transcription (that depends on the RNA sequence), 5 or $10 \mathrm{~mL}$ transcription is recommended in order to obtain enough RNA for the preparation of one to three NMR samples (ranging from 0.5 to $1 \mathrm{mM}$ concentration in a typical $250-300 \mu \mathrm{L}$ volume). Mix gently after each addition. Add the optimal amount of $\mathrm{MgCl}_{2}$ (around 20-40 mM) (see Note 6) and the two complementary DNA strands (around $1 \mu \mathrm{M})$ (see Note 12). Aliquot the solution in $1.5 \mathrm{~mL}$ plastic tubes, each containing up to $1 \mathrm{~mL}$ transcription solution. Only at this point add the polymerase (stored at $-20^{\circ} \mathrm{C}$ until its usage) to each transcription tube (see Note 13). For a practical example of the needed amount of transcription reagents, see Table 1. Incubate the transcription tubes for 4 to 12 hours at $37^{\circ} \mathrm{C}$, shaking at $300 \mathrm{rpm}$ (see Notes $\mathbf{1 3}$ 
and 14).

2. If the transcription works well, a white precipitate due to $\mathrm{Mg}_{2} \mathrm{P}_{2} \mathrm{O}_{7}$ (magnesium pyrophosphate) formation is usually visible. Spin down the magnesium pyrophosphate and transfer $2.5 \mathrm{~mL}$ each of the supernatant in $12 \mathrm{~mL}$ centrifuge compatible plastic tubes. Precipitate the solutions with 3 volumes of $100 \% \mathrm{EtOH}$ and $1 / 20$ volume of $5 \mathrm{M} \mathrm{NaCl}$, either overnight at $-20^{\circ} \mathrm{C}$ or at $-80^{\circ} \mathrm{C}$ for one hour. Thereafter centrifuge the frozen tubes at $4{ }^{\circ} \mathrm{C}$ for 30 minutes at $13^{\prime} 000 \mathrm{~g}$, collect the RNA precipitate and dry it in vacuum for few minutes. 3. Prepare for the gel electrophoresis. Wipe the gel plates, spacers and combs with ultrapure water and 70\% EtOH, assemble them on a horizontal surface and fix them with clamps. For a $5 \mathrm{~mL}$ transcription, it is advisable to prepare two big gels $(45 \times 30 \mathrm{~cm}$ with 1.5 $\mathrm{mm}$ spacers). For each gel, transfer about $200 \mathrm{~mL}$ of gel solution (prepared the day before and stored at $4^{\circ} \mathrm{C}$ ) to an autoclaved beaker, add $1 \mathrm{~mL}$ of APS and $120 \mu \mathrm{L}$ of TEMED. Gently mix the solution with a plastic syringe and pour it into the pre-assembled glass plates. Try to avoid bubbles by gently tapping the glass with your knuckles during pouring. When the plates are filled place the combs. The gel will take around 1 hour to polymerize.

4. After polymerization remove the combs and place the gels in the vertical electrophoresis gel apparatus. Fix them to the upper chambers with clamps. Fill the upper and the lower chambers with 1x TBE running buffer. Pre-run the gels for 10 minutes. Dissolve the dried RNA in a total volume of $0.5-1 \mathrm{~mL}$ of ultrapure water, add the same amount of denaturing urea loading buffer and load the sample. Use a maximum of $1.5 \mathrm{~mL}$ of sample for each gel. Run the gels. For example, $18 \%$ gels can be run overnight at low power $(10-15 \mathrm{~W}$ per gel) or during the day at higher power (30-40 W per gel) (see Note 15).

5. Stop the electrophoresis when the RNA reaches the lower third of the gel. Disassemble the gel with the use of a thin spatula and place it on a piece of cellophane. Put it under a 260 nm UV lamp in order to visualize the RNA sample. Excise it from the gel by cutting the band 
in 3-8 $\mathrm{mm}$ pieces with a scalpel.

6. Recover the RNA sample by electroelution at $200 \mathrm{~V}$ at room temperature into the smallest volume possible using an electroelution system with BT1 and BT2 membranes (Whatman ${ }^{\circledR}$ Elutrap System). Normally the electroelution procedure is repeated 2-3 times, each lasting for 1-2 hours. The collected solution is precipitated with $\mathrm{EtOH}$ and $\mathrm{NaCl}$, as described above. Check by UV-shadowing if all the RNA has been recovered from the gel. 7. Centrifuge the solutions containing RNA ( 30 minutes, $13^{\prime} 000 \mathrm{~g}$, at $4^{\circ} \mathrm{C}$ ), collect the RNA pellets and dry them in vacuum.

\subsection{Preparation, Purification and Concentration of the NMR Samples.}

The sample for metal titration NMR measurements must contain only RNA (and the needed amount of salt for folding, see below). All buffers used during transcription (especially TRIS, which is a good chelating ligand for metal ions (24)) as well as water soluble acrylamide impurities must be carefully and completely removed.

1. The isolated RNA is purified by centrifugation (Vivaspin $2 \mathrm{~mL}$ ultrafiltration devices, Sartorius Stedim biotech) with several washing steps employing first $1 \mathrm{M} \mathrm{KCl}$ and then ultrapure water (see Notes 16 and 17). For example, for a $300 \mu \mathrm{L}$ of a $0.5 \mathrm{mM}$ sample, the washing procedure must be repeated at least 5 times with $1 \mathrm{M} \mathrm{KCl}$ at $\mathrm{pH} 7.5-8$ and 5 times with ultrapure water at room temperature at the speed recommended by ultrafiltration devices suppliers. Each time the volume of the sample should be reduce from $2 \mathrm{~mL}$ to about $300 \mu \mathrm{L}$. Centrifugation time can vary from 10 to 30 minutes according to the sample concentration. 2. After several rinsing cycles, collect the sample and check its concentration by UV measuring the absorption at $260 \mathrm{~nm}$. According to its concentration and intended usage divide the sample into aliquots and lyophilize them (see Notes 18 and 19).

3. Dissolve the previously lyophilized RNA in $100 \% \mathrm{D}_{2} \mathrm{O}$, in the presence of the needed 
amount of $\mathrm{KCl}$ (see Notes 20 and 21). The ideal sample concentration is around $0.5-1 \mathrm{mM}$. (see Notes 22). Add 4-8 $\mu \mathrm{L}$ of $1 \mathrm{mM}$ EDTA in $\mathrm{D}_{2} \mathrm{O}$ (up to $10 \mu \mathrm{M}$ concentration) in order to chelate transition metal ion impurities that may be present in the sample. Adjust the $\mathrm{pH}$ using $\mathrm{DCl}$ and/or NaOD solutions (see Notes 23 and 24) and check again the concentration by UV. 4. Transfer the sample into a $5 \mathrm{~mm}$ Shigemi tube, ideally in $300 \mu \mathrm{L}$ of total volume (see Notes 25 and 26).

\subsection{NMR Measurements: $\left[{ }^{1} H,{ }^{1} H\right]-N O E S Y$ and ${ }^{2} J-\left[{ }^{1} H,{ }^{15} N\right]-H S Q C$ Experiments.}

The sample is now ready for the NMR measurements. To obtain a good resolution at reasonable experimental time, the spectrometers used for bio-NMR experiments normally have magnetic fields of $500 \mathrm{MHz}$ or higher and are equipped with $\mathrm{z}$-axis pulsed field gradient cryoprobes $^{\mathrm{TM}}$ (Bruker) or cold probes (Varian/Agilent). Even if the experiments here described are performed in $\mathrm{D}_{2} \mathrm{O}$ it is important to find the right conditions for water suppression.

The scope of the experiments described below is to observe the chemical shift changes of ${ }^{1} \mathrm{H}$ and ${ }^{15} \mathrm{~N}$ upon metal ion titration and use these changes to describe qualitatively and quantitatively the studied RNA-metal ions system.

1. Record a series of ${ }^{1} \mathrm{H}-\mathrm{NMR}$ spectra at different temperatures and $\mathrm{KCl}$ concentrations (see Note 20), evaluate the line-width of the resonances and set the conditions which are best. Normally, the temperatures used are between $293 \mathrm{~K}$ and $310 \mathrm{~K}$.

2. If sugar and aromatic proton chemical shift changes are followed, $\left[{ }^{1} \mathrm{H},{ }^{1} \mathrm{H}\right]-\mathrm{NOESY}$ experiments are best suited (Fig. 3b, see Note 27). Usually, only the H1' are followed as all other sugar protons suffer from a strong overlap. To observe N7-H8 chemical shift changes, ${ }^{2} J-\left[{ }^{1} \mathrm{H},{ }^{15} \mathrm{~N}\right]-\mathrm{HSQC}$ experiments (Figs. 3c and 4, see Notes 28, 29 and 30) with a ${ }^{15} \mathrm{~N}$ labeled RNA sample should be recorded. 
3. After recording the first experiments at $0 \mathrm{mM} \mathrm{M}^{\mathrm{n}+}$ concentration start the metal ion titration: a defined amount of $\mathrm{MgCl}_{2}$ solution in $\mathrm{D}_{2} \mathrm{O}$ (normally $1 \mu \mathrm{L}$ additions are performed) is laid on the inner NMR tube wall. The tube is covered with Para-Film and the solution gently mixed (see Note 31). The tube can also be centrifuged with a NMR tube table centrifuge. Strong line broadening of ${ }^{15} \mathrm{~N}$ resonances is often observed already in the presence of $2.5 \mathrm{mM} \mathrm{Mg}^{2+}$ while, in the case of ${ }^{1} \mathrm{H}$ resonances, a larger concentration range of up to 10$15 \mathrm{mM} \mathrm{Mg}^{2+}$ is possible (21). Depending on which nucleus is observed, perform $0.5 \mathrm{mM}$ or 1 $\mathrm{mM}$ addition steps (see Note $\mathbf{3 2}$ and $\mathbf{3 3}$ ).

4. Repeat the NMR experiments without changing parameters at each titration steps. Only the $90^{\circ}$ pulse and the field homogeneity must be checked after every addition, as well as the number of scans (see Notes 27, 28 and 34).

5. When the titration experiment is finished remove the $\mathrm{Mg}^{2+}$ as soon as possible. In order to do that, purify the sample with PAGE electrophoresis, followed by electroelution (see above) (see Note 35). Clean the Shigemi tube with ultrapure water, $0.1 \mathrm{M}$ EDTA and EtOH. Alternatively, add an excess of EDTA to the NMR sample to chelate magnesium and purify it by centrifugation (see above).

\subsection{Data Treatment and Evaluation of Affinity constants.}

In order to obtain meaningful data as many ${ }^{1} \mathrm{H}$ and ${ }^{15} \mathrm{~N}$ resonances of the studied RNA sample must be attributed, e.g. by the sequential walk strategy, as described elsewhere $(\mathbf{8 , 2 5})$.

Perform at least 10-12 titration steps in order to obtain a reliable fit of the experimental data and accurate affinity constants.

\subsubsection{Qualitative Evaluation of ${ }^{1} \mathrm{H}$ Data.}

1. Map the ${ }^{1} \mathrm{H}$ chemical shift variations $(\Delta \delta)$ of as many peaks as possible based on the 
$\left[{ }^{1} \mathrm{H},{ }^{1} \mathrm{H}\right]-\mathrm{NOESY}$ experiments and tabulate them.

2. Calculate the $\Delta \delta$ values at each step of $\mathrm{Mg}^{2+}$ addition and plot them in a bar diagram to qualitatively obtain a first picture of $\mathrm{Mg}^{2+}$ binding and $\mathrm{Mg}^{2+}$-induced structure perturbation. The observed $\Delta \delta$ values, both upfield and downfield, are normally in the range 0.05-0.25 ppm. Usually, an upfield shift is due to an increase in stacking interaction attributable to metal ion binding nearby, while the downfield shift can be attributed to a decrease in stacking interactions and/or the electron-pulling effect of metal ion coordination. The plot of $\Delta \delta$ versus $\mathrm{Mg}^{2+}$ concentration offers a qualitative, easy and clear picture of metal ion binding and allows to divide the RNA molecule in few binding regions. This is a good starting point for the following steps of data analysis consisting in the quantitative evaluation of the binding.

\subsubsection{Estimating the Affinity Constants.}

1. Plot the chemical shifts of the observed protons versus the increasing total $\mathrm{Mg}^{2+}$ concentration.

2. Fit the data to equation 1 , corresponding to a 1:1 binding model, using for example a Levenberg-Marquardt non-linear least square fit algorithm, to calculate the affinity constant $K_{A i}$ of $\mathrm{Mg}^{2+}$ towards a binding site $i$ in the RNA molecule (see Note 36). This can be done with software like Origin, Matlab ${ }^{\circledR}$ or similar mathematical programs yielding first preliminary affinity constants. In equation $1,\left[\mathrm{RNA}_{\mathrm{i}}\right]_{\text {tot }}$ corresponds to the total RNA concentration and $\left[\mathrm{M}^{\mathrm{n}+}\right]_{\text {tot }}$ to the total increasing magnesium concentration. $\delta_{\mathrm{obs}}$ is the chemical shift of the observed proton while $\delta_{\mathrm{RNAi}}$ and $\delta_{\mathrm{RNA}} \bullet \mathrm{M}$ are the chemical shifts of the unbound and completely bound species, respectively.

$\delta_{o b s}=\delta_{R N A i}+\left(\delta_{R N A \bullet M}-\delta_{R N A i}\right) \frac{\left[M^{n+}\right]_{o t}+\left[R N A_{i}\right]_{t o t}+\frac{1}{K_{A i}}-\sqrt{\left(\left[M^{n+}\right]_{o o t}+\left[R N A_{i}\right]_{o t}+\frac{1}{K_{A i}}\right)^{2}-4\left[M^{n+}\right]_{o t}\left[R N A_{i}\right]_{t o t}}}{2\left[R N A_{i}\right]_{o t}}$ 
3. Group the binding constants estimated with equation 1 into binding sites according to their similar values and neighborhood. The qualitative plot of $\Delta \delta$ thereby helps to define binding regions.

4. Use $\mathrm{Mn}^{2+}$ line broadening experiments to confirm the different binding sites within the molecule. (see Note 37)

5. Calculate averaged affinity constants $K_{A, a v l i}$ by taking either the arithmetic or weighted mean of the respective $K_{A i}$ values for each binding site.

\subsubsection{Determination of the Intrinsic Affinity Constants.}

Usually more than one $\mathrm{Mg}^{2+}$ coordination site with similar affinity is present in RNA.

Consequently, the various binding sites are filled in parallel and the amount of $\mathrm{Mg}^{2+}$ available for each site is smaller than the total $\mathrm{Mg}^{2+}$. The average affinity constants obtained as described in Section 3.4.2 do not take this effect into account. To determine the intrinsic affinity constant for a given site, $\left[\mathrm{M}^{\mathrm{n}+}\right]_{\text {tot }}$ in equation 1 must be substituted by the actual available $\mathrm{Mg}^{2+}$ concentration (20).

1. Use the obtained $K_{A, a v l i}$ values to calculate the concentration of bound $\mathrm{Mg}^{2+}$, $\left[\mathrm{M}^{\mathrm{n}+}\right]_{\text {bound,i }}$, at each binding site with equation 2.

$$
\left[M^{n+}\right]_{\text {bound }, i}=\frac{\left(K_{A, a v i l}\left[M^{n+}\right]_{\text {tot }}+K_{A, \text { avi }}[R N A]_{\text {tot }}+1\right)-\sqrt{\left(-\left(K_{A, a v i l}\left[M^{n+}\right]_{\text {oto }}+K_{A, a v i l}[R N A]_{\text {tot }}+1\right)\right)^{2}-4 K_{A, a v i l}{ }^{2}\left[M^{n+}\right]_{\text {oot }}[R N A]_{\text {tot }}}}{2 K_{A i}}
$$

2. Calculate the actual available $\mathrm{Mg}^{2+}$ concentration, $\left[\mathrm{M}^{\mathrm{n}+}\right]_{\text {avail, }, \text {, }}$ using equation 3 , where $\left[\mathrm{M}^{\mathrm{n}+}\right]_{\text {bound }}$ corresponds to the sum of the concentrations of $\mathrm{Mg}^{2+}$ bound to all binding sites.

$$
\left\lfloor M^{n+}\right\rfloor_{\text {avail }, i}=\left[M^{n+}\right]_{\text {ot }}-\sum\left[M^{n+}\right]_{\text {bound }}+\left[M^{n+}\right]_{\text {bound }, i}
$$

3. Fit again the chemical shift data versus the corrected concentration $\left[\mathrm{M}^{\mathrm{n}+}\right]_{\mathrm{avail}, \mathrm{i}}$ at each binding site using equation 1 . New affinity constants are obtained and again averaged for each individual binding site, to give a second set of average affinity constants $K_{A, a v 2 i}$ (Fig. 3d). 
4. Insert these new affinity constants in equation 2 and 3 to calculate an improved value for $\left[\mathrm{M}^{\mathrm{n}+}\right]_{\text {bound }, i}$ and $\left[\mathrm{M}^{\mathrm{n}+}\right]_{\text {avail, } i}$ for each individual binding site (Fig. 3d,e).

5. Repeat the procedure iteratively until no changes in $K_{A, a v}$ are observed anymore within the error limit (Fig. 3d,e).

6. Plot the $K_{A, a v}$ values for each iteration step versus the corresponding iteration round and fit them to an asymptotic function in order to obtain the final intrinsic affinity constant for each binding site (Fig. 3e).

Naturally, the above described calculation procedure is not restricted to $\mathrm{Mg}^{2+}$ binding but can be applied to any system that contains multiple binding sites for the same ligand at similar affinities. In Notes $\mathbf{3 8}$ and 39 details of this procedure for an example case are given.

\subsubsection{Qualitative Evaluation of ${ }^{15} \mathrm{~N}$ Chemical Shift Changes.}

Proton chemical shift changes in such experiments can have different causes, i.e. direct metal ion coordination or conformational changes in the RNA structure due to metal ion binding close by. Extending the investigations into the ${ }^{15} \mathrm{~N}$ dimension, often allows to distinguish between these two cases and possibly even to identify the exact coordinating ligand.

1. Record ${ }^{2} J-\left[{ }^{1} \mathrm{H},{ }^{15} \mathrm{~N}\right]-\mathrm{HSQC}$ experiments during a metal ion titration (see Note 40). To obtain a qualitative picture overlay to compare the behavior of the single resonances (Fig. 3c). You can also map both ${ }^{1} \mathrm{H}$ and ${ }^{15} \mathrm{~N}$ chemical shifts as described in Section 3.4.1.

2. Analyze the shifts according to the following qualitative rules: In case shift changes in either ${ }^{15} \mathrm{~N}$ or both dimensions and a sever line broadening is observed, this can be taken as evidence for a direct (inner-sphere) $\mathrm{Mg}^{2+}-\mathrm{N}$ coordination (A15 in Fig. 3c) based on the fast ligand exchange rate of $\mathrm{Mg}^{2+}$. If only the ${ }^{1} \mathrm{H}$ but not in the ${ }^{15} \mathrm{~N}$ chemical shift is affected (A20 in Fig. 3c) structural changes are the cause. If both ${ }^{1} \mathrm{H}$ and ${ }^{15} \mathrm{~N}$ signals are shifted but without line broadening outer sphere interaction is probably the cause (see Note 41). 


\section{Notes}

1. In order to minimize dilution, first add $5 \mathrm{M} \mathrm{NaOH}$ and then add $\mathrm{NaOH}$ of lower concentration $(1 \mathrm{M}, 100 \mathrm{mM}, 10 \mathrm{mM})$ to reach the desired $\mathrm{pH} . \mathrm{HCl}$ solution at different concentration can be used to decrease the $\mathrm{pH}$ again if too much base has been added.

2. Use the following extinction coefficients of the nucleotides $\left(\mathrm{M}^{-1} \mathrm{~cm}^{-1}\right): \varepsilon_{\text {ATP }}(260 \mathrm{~nm})$

$=15.4 \cdot 10^{3}, \varepsilon_{\mathrm{UTP}}(260 \mathrm{~nm})=10.0 \cdot 10^{3}, \varepsilon_{\mathrm{CTP}}(270 \mathrm{~nm})=9.0 \cdot 10^{3}, \varepsilon_{\mathrm{GTP}}(249 \mathrm{~nm})=13.7 \cdot 10^{3}$.

3. In principle, only the T7 promoter region must be double stranded. However, our experience shows that higher transcription yields are reached by using fully double stranded DNA oligonucleotides.

4. For RNA sequences comprising more than 50 nucleotides synthetic double stranded DNA oligonucleotides are usually substituted by cut plasmids. Nevertheless, RNA samples used for NMR experiments are mostly shorter than 40-50 nucleotides.

5. The efficiency of the T7 RNA polymerase depends critically on the first six nucleotides of the transcription. Most importantly, a 5'-guanosine is a prerequisite. 5'GGGAGA, 5'-GGGAUC, and 5'-GAGCGG are known to be good starting sequences. For a collection of good starting sequences, see also reference (26).

6. Note, $\mathrm{MgCl}_{2}$ is not a titrimetric standard. The $\mathrm{MgCl}_{2}$ concentration is crucial for the transcription yield and must be optimized for each sequence. In order to do so, transcription trials are performed on $50 \mu \mathrm{L}$ scale. The efficiency of the transcription is checked with an analytical gel. In our experience, a $35 \mathrm{mM}$ concentration is optimal for transcription of relatively short RNAs $(<50 \mathrm{nt})$.

7. Bacteriophage T7 RNA polymerase does not do a primer extension but rather starts from a single GTP, which makes it useful for in vitro transcriptions. However, T7 tends to 
add one or more random nucleotides at the 3'- end of the run-off transcription, leading to problems with $3^{\prime}$ homogeneity. A way to circumvent $3^{\prime}$ - and 5'- inhomogeneous ends can be found in references $(\mathbf{2 2}, \mathbf{2 7})$. T7 can be obtained commercially, but for the large scale of NMR transcriptions it is advisable to express it oneself. An easy-reading protocol on T7 RNA polymerase preparation and its use for in vitro transcription has been published recently (22). 8. For fragments comprising 30-50 nucleotides use $18 \%$ polyacrylamide gel solution. For longer fragments, use lower percentage of polyacrylamide (28). Safety note: unpolymerized acrylamide is a neurotoxin. To avoid skin contact, wear protection gloves and glasses as well as a lab coat while handling.

9. The dyes normally used are xylene cyanol (XC) and bromophenol blue (BB), whose migration in polyacrylamide denaturing gels is known (28). For very short RNAs also Orange G can be used, which runs with a dinucleotide.

10. $100 \%$ refers normally to a minimum of $99.98 \% \mathrm{D}_{2} \mathrm{O}$ isotope enrichment. Buy small bottles (10 mL maximum) and store them at room temperature. Repeated opening and closing of the bottle causes an increasing of $\mathrm{H}_{2} \mathrm{O}$ content.

11. Labeled nucleotides $\left({ }^{13} \mathrm{C}\right.$ and/or $\left.{ }^{15} \mathrm{~N}\right)$ are nowadays normally purchased from a commercial supplier (e.g., Silantes $\mathrm{GmbH}$ ). In the past, such nucleotides had prohibitive prices and different routes for their synthesis were proposed $(\mathbf{8}, \mathbf{1 2})$. In the last few years more competitive prices made it possible to overcome the need of synthesizing them for most applications.

12. As for the $\mathrm{MgCl}_{2}$ concentration (see Note 6), the amount of DNA used in transcription must be optimized. This is best done by performing $50 \mu \mathrm{L}$ transcription trials in the presence of different amount of DNA and evaluating the transcription efficiency with an analytical gel. In our experience the best concentration of DNA is between 0.6 and $1.2 \mu \mathrm{M}$.

13. The amount of T7 RNA polymerase to be used depends on its efficiency and stock 
concentration, which must be checked any time a new polymerase batch is prepared. Again this is best done by $50 \mu \mathrm{L}$ transcription trials with varying $\mathrm{T} 7$ concentrations and evaluated on analytical gels. The optimal duration of the transcription depends on the RNA sequence and must be checked independently. Longer sequences tend to degrade if too long transcription times are used.

14. During transcription, metal ion assisted partial hydrolysis of the terminal NTP seems to occur, leading to a mixture of a $5^{\prime}$ terminal tri- and di-phosphate groups. Once the sample is prepared no further change in the ratio of diphosphate and triphosphate terminal groups seems to occur (20).

15. A $\mathrm{n} / \mathrm{n}+1$ nucleotide resolution can be reached by using the right percentage of acrylamide, not overloading the gel and performing long runs. Other separation techniques based on chromatographic methods are also known but will not be discussed here (29). 16. Before usage, the filter devices must be rinsed following the instructions of the supplier. Choose the filter devices according to the molecular weight of the sample. For a good recovery of RNA the membrane cut-off should be at least $50 \%$ smaller than the molecular weight of the RNA. For RNAs used for NMR, which normally range from 7 to 20 $\mathrm{kDa}$, membranes with $3 \mathrm{kDa}$ cut-off are advisable.

17. This point is very critical in order to prepare a sample useful for metal titration studies: TRIS used in the transcription buffer is a good chelating ligand for metal ions (24) and must be completely removed to obtain reliable values of affinity constants.

18. The lyophilized RNA can be stored in a closed vial at $-20^{\circ} \mathrm{C}$ up to several months without risk of degradation.

19. If hairpins are investigated, it is important to verify that a hairpin and not a duplex is formed in solution. To avoid duplex formation and any possible association events one possibility is to dilute the RNA sample with up to $100 \mathrm{~mL}$ of ultrapure water, denature the 
RNA at $80-90{ }^{\circ} \mathrm{C}$ in a water bath and cool it again on ice. It is better using glassware instead of plastic vessels which can release plasticizers into RNA sample upon heating. Concentrate the sample by centrifugation and lyophilization.

20. $\mathrm{KCl}$ binds unspecifically to RNA and is needed to ensure the proper RNA secondary structure. Its concentration normally ranges from 50 to $100 \mathrm{mM}$.

21. Often phosphate buffers are used in NMR samples. This must be strictly avoided when performing metal ion titrations, as phosphate is a good ligand for metal ions (30).

22. Aggregates can form at higher concentration, which hamper the quality of the spectra. Aggregates can be detected by NMR diffusion experiments (DOSY) or spectroscopically by dynamic light scattering (DLS) (16).

23. The ideal $\mathrm{pH}$ is close to neutrality or slightly acidic. In our experience, the best $\mathrm{pH}$ range is between 6.7 and 7.2. RNA is sensitive to alkaline conditions, at which it undergoes base catalyzed hydrolysis.

24. As the NMR solution is prepared in $\mathrm{D}_{2} \mathrm{O}, 0.4 \log$ units have to be added to the $\mathrm{pH}-$ meter reading in order to get the correct $\mathrm{pD}$ value (31).

25. Shigemi tubes are special NMR microtubes, whose magnetic susceptibility is matched to a specific solvent, and which are ideal for measuring small sample amounts. They consist of an outer tube and a plunger. The solution is poured into the tube and the plunger is then carefully placed on top the solution. Care should be taken to avoid bubbles at the interface between the plunger and the sample.

26. A $200 \mu \mathrm{L}$ volume is the minimum but to have good field homogeneity it is advisable to use at least $300 \mu \mathrm{L}$. If you have only little RNA, $300 \mu \mathrm{L} 0.5 \mathrm{mM}$ sample is better than 200 $\mu \mathrm{L} 0.75 \mathrm{mM}$ sample.

27. Depending on the sample concentration, 5 to 8 hours for a $\left[{ }^{1} \mathrm{H},{ }^{1} \mathrm{H}\right]$-NOESY spectrum are required. With increasing amounts of $\mathrm{Mg}^{2+}$, the peaks get broader and more scans are 
needed in order to obtain a good signal to noise ratio. Consequently the last points of the titration can each take up to 12 hours. As the homogeneity of the system is fundamental in order to analyze the data, it is advisable to finish the titration within a reasonable time. i.e. one needs at least 4-5 consecutive days of measuring time. The same mixing time should be used in all the experiments $(200-250 \mathrm{~ms})(\mathbf{8})$.

28. This experiment is useful to follow the chemical shift variation of $\mathrm{N} 7$ of the purine nucleobases. It uses the ${ }^{2} J$ coupling constant between N7 and H8 (32) (Fig. 4) and allows to contemporary follow $\mathrm{N} 7$ and $\mathrm{H} 8$ chemical shift perturbation upon $\mathrm{Mg}^{2+}$ titration (21). As in the case of the $\left[{ }^{1} \mathrm{H},{ }^{1} \mathrm{H}\right]$-NOESY (see Note 27), these experiments can take up to 8-10 hours at high $\mathrm{Mg}^{2+}$ concentration.

29. The samples used for these experiments can be fully or partly ${ }^{13} \mathrm{C},{ }^{15} \mathrm{~N}$ or only ${ }^{15} \mathrm{~N}$ labeled. In case a ${ }^{13} \mathrm{C},{ }^{15} \mathrm{~N}$ labeled sample is used, ${ }^{13} \mathrm{C}$ and ${ }^{15} \mathrm{~N}$ need to be simultaneously decoupled. Samples can be prepared in which only adenosines or only guanosines are labeled. Although time consuming, the use of different samples containing only one kind of labeled nucleotide at a time allows a straightforward and unambiguous attribution of the peaks. 30. In our experience ${ }^{2} J-\left[{ }^{1} \mathrm{H},{ }^{15} \mathrm{~N}\right]-\mathrm{HSQC}$ experiments comprising a selective $180^{\circ}{ }^{15} \mathrm{~N}$ IBurp2 shaped pulse give good results (21).

31. If folding needs to start from single stranded RNA, the solution is transferred to a 1.5 $\mathrm{mL}$ plastic tube. The solution is warmed up using a heating plate, $\mathrm{MgCl}_{2}$ is added, the solution mixed by a vortex mixer, and cooled down on ice before transferred back into the NMR tube. Such, mixing is most effective but usually leads to a considerable loss of sample after a few titration steps.

32. Here, we describe the titration using $\mathrm{MgCl}_{2}$ but with other metal ions it works accordingly. For example $\mathrm{MnCl}_{2}$ and $\mathrm{CaCl}_{2}$ can be used. In the case of $\mathrm{Cd}^{2+}$ it is important to use $\mathrm{Cd}\left(\mathrm{ClO}_{4}\right)_{2}$ and replace $\mathrm{KCl}$ with $\mathrm{NaClO}_{4}$ because $\mathrm{CdCl}^{+}$is a rather stable complex in 
solution.

33. $\mathrm{Mg}^{2+}$ binding is responsible for both chemical shift changes and signal line broadening due to the ligand exchange rate on the NMR timescale. Nevertheless, evaluating both the proton chemical shift changes and their line broadening allows to depict an accurate picture of the metal ion binding sites (33).

34. High concentration of salt increases the pulse length and may hamper proper tuning and matching.

35. $\mathrm{M}^{2+}$ ions tend to facilitate hydrolysis, resulting in RNA degradation. After performing the metal ion titration make sure that you have all the data needed and desalt the sample before starting the data analysis.

36. Chemical shifts of aromatic and sugar $\mathrm{H} 1$ ' protons are usually best dispersed and provide the best data. Also imino protons can be investigated (in $90 \% \mathrm{H}_{2} \mathrm{O} / 10 \% \mathrm{D}_{2} \mathrm{O}$ ) but can often not be properly fit to a 1:1 binding model because of solvent exchange phenomena (34).

37. These experiments are performed following the above described procedure (20): $\left[{ }^{1} \mathrm{H},{ }^{1} \mathrm{H}\right]-\mathrm{NOESY}$ experiments are recorded at each titration steps, from 0 to $200 \mu \mathrm{M} \mathrm{Mn}{ }^{2+}$ concentration, in 10-20 $\mu \mathrm{M}$ addition steps. $\mathrm{MnCl}_{2}$ should be added in smaller steps than with $\mathrm{Mg}^{2+}$ because strong line broadening is observed already at very low $\mathrm{Mn}^{2+}$ concentration (13). Again, aromatic and $\mathrm{H} 1$ ' sugar protons are evaluated.

38. The method was used to evaluate the intrinsic affinity constants of $\mathrm{Mg}^{2+}$ to D6-27 (Fig. 3) (20). A $0.85 \mathrm{mM}$ sample $\left(100 \mathrm{mM} \mathrm{KCl}, 10 \mu \mathrm{M}\right.$ EDTA, pD $=6.7$ in $\left.100 \% \mathrm{D}_{2} \mathrm{O}\right)$ was titrated with increasing amounts of $\mathrm{Mg}^{2+}$ (0 to $12 \mathrm{mM}$ in eleven steps) and $\left[{ }^{1} \mathrm{H},{ }^{1} \mathrm{H}\right]-\mathrm{NOESY}$ experiments were collected at any step at $303 \mathrm{~K}$. The ${ }^{1} \mathrm{H}$ changes were plotted against $\mathrm{Mg}^{2+}$ concentration and (if possible) fit to equation 1 with a Levenberg-Marquardt non-linear least square regression. Preliminary affinity constants $K_{A, \text { est }}$ were calculated using the total 
concentration of $\mathrm{Mg}^{2+}$ in solution and grouped into five individual binding sites on the basis of their value, their proximity, and $\mathrm{Mn}^{2+}$ line broadening to determine averaged $K_{A, a v}$ values for each binding site. These values were inserted in equations 2 and 3 to calculate the actual $\mathrm{Mg}^{2+}$ concentration. The corrected $\mathrm{Mg}^{2+}$ concentrations were then used in equation 1 in the next iteration step to obtain improved $K_{A, \text { est }}$ values. This iterative procedure was repeated until the calculated intrinsic affinity constants did not change anymore within the experimental errors (Fig. 3d,e). The final intrinsic affinity constants as well as the five binding sites to which they refer are shown in Fig. 3a (20).

39. Particular attention needs to be paid when evaluating the affinity constants at the $5^{\prime}$ terminus. As stated in Note 14, 5'-triphosphate and 5'-diphosphate terminal groups are usually present after transcription, both of which are good $\mathrm{Mg}^{2+}$ binding sites (20). First, the exact ratio (based on NOE cross peaks ratio or ${ }^{31} \mathrm{P}$ signals) must be determined. Second, in contrast to all the other binding sites, whose $\mathrm{p} K_{a}$ values are far away from neutrality, at $\mathrm{pD} 6.7$ (at which titration of D6-27 were performed) competition between $\mathrm{D}^{+}$and $\mathrm{Mg}^{2+}$ occurs (NTP, $\mathrm{p} K_{\mathrm{a} / \mathrm{H} 2 \mathrm{O}}=6.50 \pm 0.05$, and NDP, $\left.\mathrm{p} K_{\mathrm{a} / \mathrm{H} 2 \mathrm{O}}=6.40 \pm 0.05\right)(\mathbf{2 0})$. The apparent affinity constants at 5 '-termini can then be corrected using equation $4 . K_{\mathrm{a} / \mathrm{D} 2 \mathrm{O}}$ represents the acidity constant of the tri-/diphosphate in $\mathrm{D}_{2} \mathrm{O}$, calculated according to equation 5 .

$$
\begin{aligned}
& \log K_{A, D P / T P}=\log K_{A, D P / T P}^{a p p}+\log \left(1+\frac{\left[D^{+}\right]}{K_{a / D_{2} O}}\right) \\
& p K_{a / D_{2} O}=1.015 \cdot p K_{a / H_{2} O}+0.45
\end{aligned}
$$

40. For example, this method was used to study the interaction between D6-27 (Fig. 3c) and $\mathrm{Mg}^{2+}$. Different samples were prepared, with either only guanosines or only adenosines ${ }^{13} \mathrm{C}$ and ${ }^{15} \mathrm{~N}$ labeled (concentration ranging from 0.5 to $1.57 \mathrm{mM}, 50 \mathrm{mM} \mathrm{KCl}, 10 \mu \mathrm{M}$ EDTA, $\mathrm{pD}=6.7$ ). The samples were titrated with $\mathrm{Mg}^{2+}$ from 0 to $2.5 \mathrm{mM}$, in $0.5 \mathrm{mM}$ steps. At any step, ${ }^{2} J-\left[{ }^{1} \mathrm{H},{ }^{15} \mathrm{~N}\right]-\mathrm{HSQC}$ experiments were recorded, at $298 \mathrm{~K}$. The ${ }^{15} \mathrm{~N}$ chemical shift 
variation observed upon $\mathrm{Mg}^{2+}$ titration were small (lower than $2 \mathrm{ppm}$ ) but allowed to give insights into the nature of the interaction (21).

41. If enough titration steps have been performed and the data is of high enough quality also a quantitative evaluation is possible as described in Sections 3.4.2 and 3.4.3.

\section{Acknowledgements}

Financial support by the $7^{\text {th }}$ European Community Framework Program (Marie-Curie Postdoctoral Fellowship to D. D. and ERC Starting Grant 2010 to R. K. O. S.), the Swiss National Science Foundation (Project 200021-124834/1 to R. K. O. S.) and the University of Zürich is gratefully acknowledged.

\section{References}

1. Gesteland, R. F., Cech, T. R., Atkins, J. F. (2006) The RNA World, Cold Spring Harbor Press.

2. Kruger, K., Grabowski, P. J., Zaug, A. J., Sands, J., Gottschling, D. E., Cech, T. R. (1982) Self-splicing RNA: autoexcision and autocyclization of the ribosomal RNA intervening sequence of Tetrahymena. Cell 31, 147-157.

3. Guerrier-Takada, C., Gardiner, K., Marsh, T., Pace, N., Altman, S. (1983) The RNA moiety of ribonuclease $\mathrm{P}$ is the catalytic subunit of the enzyme. Cell 35, 849-857.

4. Sigel, R. K. O. (2005) Group II intron ribozymes and metal ions - a delicate relationship. Eur J Inorg Chem 12, 2281-2292.

5. Freisinger, E., Sigel, R. K. O. (2007) From nucleotides to ribozymes - a comparison of their metal ion binding properties. Coord Chem Rev 251, 1834-1851. 
6. Stahley, M. R., Strobel, S. A. (2005) Structural evidence for a two-metal-ion mechanism of group I intron splicing. Science 309, 1587-1590.

7. Toor, N., Rajashankar, K., Keating, K. S., Pyle, A. M. (2008) Structural basis for exon recognition by a group II intron. Nature Struct Mol Biol 15, 1221-1222.

8. Flinders, J., Dieckmann, T. (2006) NMR spectroscopy of ribonucleic acids. Prog Nucl Mag Res Spec 48, 137-159.

9. Davis, J. H., Tonelli, M., Scott, L. G., Jaeger, L., Williamson, J. R., Butcher, S. E. (2005) RNA helical packing in solution: NMR structure of a 30kDa GAAA tetraloop-receptor complex. J Mol Biol 351, 371-382.

10. Ronconi, L., Sadler, P. J. (2008) Applications of heteronuclear NMR spectroscopy in biological and medicinal inorganic chemistry. Coord Chem Rev 252, 2239-2277.

11. Reid, S. S., Cowan, J. A. (1990) Biostructural chemistry of Magnesium ion characterization of the weak binding sites on transfer RNAphe(Yeast) - Implications for conformational change and activity. Biochemistry 29, 6025-6032.

12. Lu, K., Miyazaki, Y., Summers, M. F. (2010) Isotope labeling strategies for NMR studies of RNA. J Biomol NMR 46, 113-125.

13. Gonzalez, R. L., Jr., Tinoco, I., Jr. (2001) Identification and characterization of metal ion binding sites in RNA. Methods Enzymol 338, 421-443.

14. Johannsen, S., Korth, M. M. T., Schnabl, J., Sigel, R. K. O. (2009) Exploring Metal Ion Coordination to Nucleic Acids by NMR. Chimia 63, 146-152.

15. Tanaka, Y., Taira, K. (2005) Detection of RNA nucleobase metalation by NMR spectroscopy. Chem Commun, 2069-2079.

16. Johannsen, S., Megger, N., Bohme, D., Sigel, R. K. O., Muller, J. (2010) Solution structure of a DNA double helix with consecutive metal-mediated base pairs. Nature Chem 2, 229-234. 
17. Tanaka, Y., Oda, S., Yamaguchi, H., Kondo, Y., Kojima, C., Ono, A. (2007) ${ }^{15}$ N, ${ }^{15}$ N Jcoupling across $\mathrm{Hg}(\mathrm{II})$ : Direct observation of $\mathrm{Hg}(\mathrm{II})$-mediated $\mathrm{T}-\mathrm{T}$ base pairs in a DNA duplex. J Am Chem Soc 129, 244-245.

18. Tanaka, Y., Ono, A. (2008) Nitrogen-15 NMR spectroscopy of N-metallated nucleic acids: insights into N-15 NMR parameters and N-metal bonds. Dalton Trans, 4965-4974.

19. Maderia, M., Horton, T. E., DeRose, V. J. (2000) Metal interactions with a GAAA RNA tetraloop characterized by ${ }^{31} \mathrm{P}$ NMR and phosphorothioate substitutions. Biochemistry 39 , 8193-8200.

20. Erat, M. C., Sigel, R. K. O. (2007) Determination of the intrinsic affinities of multiple site-specific $\mathrm{Mg}^{2+}$ ions coordinated to domain 6 of a group II intron ribozyme. Inorg Chem 46, 11224-11234.

21. Erat, M. C., Kovacs, H., Sigel, R. K. O. (2010) Metal ion-N7 coordination in a ribozyme branch domain by NMR. J Inorg Biochem 104, 611-613.

22. Gallo, S., Furler, M., Sigel, R. K. O. (2005) In vitro transcription and purification of RNAs of different size. CHIMIA 59, 812-816.

23. Sigel, H., Zuberbühler, A. D., Yamauchi, O. (1991) Comments on potentiometric pH titrations and the relationship between $\mathrm{pH}$-meter reading and hydrogen ion concentration. Anal Chim Acta 255, 63-72.

24. Sigel, H., Griesser, R. (2005) Nucleoside 5'-triphosphates: Self-association, acid-base, and metal ion-binding properties in solution. Chem Soc Rev 34, 875-900.

25. Erat, M. C., Sigel, R. K. O. (2005) Structure determination of catalytic RNAs and investigations of their metal ion-binding properties. CHIMIA 59, 817-821.

26. Milligan, J. F., Groebe, D. R., Witherell, G. W., Uhlenbeck, O. C. (1987)

Oligoribonucleotide synthesis using T7 RNA polymerase and synthetic DNA templates. Nucleic Acids Res 15, 8783-8798. 
27. Erat, M. C. (2011) in "Advances in Biochemical Spectroscopy" (Pascal, S. M., and Dingley, A., Eds.), pp. in press, IOS Press, Amsterdam, The Netherlands.

28. Sambrook, J., Russel, D. W. (2001) Molecular Cloning: A Laboratory Manual, Cold Spring Harbor Laboratory Press, Cold Spring Harbor.

29. Anderson, A. C., Scaringe, S. A., Earp, B. E., Frederick, C. A. (1996) HPLC purification of RNA for crystallography and NMR. RNA 2, 110-117.

30. Schnabl, J., Sigel, R. K. O. (2010) Controlling ribozyme activity by metal ions. Curr Op Chem Biol 14, 269-275.

31. Glasoe, P. K., Long, F. A. (1960) Use of glass electrodes to measure acidities in deuterium oxide. J Phys Chem 64, 188-190.

32. Wijmenga, S. S., van Buuren, B. N. M. (1998) The use of NMR methods for conformational studies of nucleic acids. Prog Nucl Mag Res Sp 32, 287-387.

33. Erat, M. C., Zerbe, O., Fox, T., Sigel, R. K. O. (2007) Solution structure of the domain 6 from a self-splicing group II intron ribozyme: $\mathrm{A} \mathrm{Mg}^{2+}$ binding site is located close to the stacked branch adenosine. ChemBioChem 8, 306-314.

34. Sigel, R. K. O., Sashital, D. G., Abramovitz, D. L., Palmer III, A. G., Butcher, S. E., Pyle, A. M. (2004) Solution structure of domain 5 of a group II intron ribozyme reveals a new RNA motif. Nat Struct Mol Biol 11, 187-192.

35. Koradi, R., Billeter, M., Wüthrich, K. (1996) MOLMOL: A program for display and analysis of macromolecular structures. J Mol Graphics 14, 29-32 \& 51-55. 
Table 1. Practical example of the composition of a $5 \mathrm{~mL}$ transcription solution. The third column lists the final concentration of each reagent in the transcription reaction. In the fourth column the added volume of each reagent is given. Note that the efficiency of T7-RNA polymerase and thus the added amount must be checked for every new batch.

\begin{tabular}{cccc}
\hline Reagents & $\begin{array}{c}\text { Starting } \\
\text { concentration }(\mathrm{mM}) \\
\text { (stock solutions) }\end{array}$ & $\begin{array}{c}\text { Final } \\
\text { concentration }(\mathrm{mM}) \\
\text { (transcription solution) }\end{array}$ & $\begin{array}{c}\text { Needed amount } \\
(\mu \mathrm{L})\end{array}$ \\
(transcription solution)
\end{tabular}




\section{Figure Legends}

Fig. 1. General NTPs structure with atomic numbering schemes (left top) and nucleotide structure within RNA with the bridging 5'- and 3'-phosphates groups (left bottom). The chemical structures of the four most abundant natural nucleobases in RNA are given on the right together with their numbering scheme: adenine (Ade), guanine (Gua), uracil (Ura) and cytosine (Cyt). The arrows indicate the most common coordination sites for metal ions.

Fig. 2. Different coordination modes of metal ions to nucleic acids. Inner sphere (left) and outer sphere (right) coordination of $\left[\mathrm{Mg}\left(\mathrm{H}_{2} \mathrm{O}\right)_{6}\right]^{+}$to adenine-N7 is depicted.

Fig. 3. NMR solution structure (a) of the truncated domain 6 of the yeast mitochondrial group II intron Sc.ai5 (D6-27) used for the metal ions binding experiments described in Notes 38, 39 and $40(20,21)$. The five $\mathrm{Mg}^{2+}$ ions and their intrinsic $\log K_{\mathrm{a}}$ values are indicated (20). Overlaid selected regions of $\left[{ }^{1} \mathrm{H},{ }^{1} \mathrm{H}\right]$-NOESY (b) and ${ }^{2} J-\left[{ }^{1} \mathrm{H},{ }^{15} \mathrm{~N}\right]-\mathrm{HSQC}$ (c) experiments show chemical shift perturbation within D6-27 upon $\mathrm{Mg}^{2+}$ titration $(\mathbf{2 0}, \mathbf{2 1})$. Signals that broaden with increasing $\mathrm{Mg}^{2+}$ indicate direct coordination nearby whereas a "simple" change in chemical shift "just" indicates a structural change induced by neighboring $\mathrm{Mg}^{2+}$-binding. The change of a 1:1 fit (d) and of the $\log K_{\mathrm{a}, \mathrm{av}}$ values of a RNA with three binding sites (e) upon the iterative calculation procedure of intrinsic affinity constants is schematically indicated. Panel (b) was prepared with MOLMOL (35) using PDB ID 2AHT. Figure 3c is adapted from (21).

Fig. 4. ${ }^{1} \mathrm{H},{ }^{15} \mathrm{~N}$ long range coupling between $\mathrm{H} 8$ and $\mathrm{N} 7$ of adenine and guanosine nucleobases as observed by the ${ }^{2} J-\left[{ }^{1} \mathrm{H},{ }^{15} \mathrm{~N}\right]-\mathrm{HSQC}$ experiment (see Fig. 3c). 